\title{
Rüzgar Türbinlerinde İşletme ve Bakım
}

\author{
Harun Kemal Öztürk
}

\section{ÖZ}

Enerji tüketimi nüfus artışı, sanayileşme ve konfor seviyesinin artmasına bağlı olarak artmaktadır. Diğer yandan, günümüzde enerji tüketiminin çok büyük kısmının sağlandığı fosil yakıtlar, iklim değişikliği ve çevresel kirliliğe neden olmaktadır. Bu nedenle de, yenilenebilir enerji kaynakları ön plana çıkmaktadır. Yenilenebilir enerji kaynakları içerisinde ise rüzgar enerjisi, ilk yatırım ve işletme maliyetleri göz önüne alındığında ön plana çıkmaktadır. Rüzgar türbinlerinde arızalar nedeni ile meydana gelebilecek duraksamalar yatırımcıların istemediği konular içerisinde yer almaktadır. Rüzgar türbinlerinin mekanik ve elektriksel aksamları göz önüne alındığında, en çok arızanın elektriksel aksamlardan kaynaklandığı ancak mekanik arızalar sırasındaki duraksamaların ise daha uzun süreler aldığı gözlemlenmiştir. Rüzgar türbinlerinde yapılacak bakım çalışmaları ile hem arızaların önüne geçilebilmekte hem de duraksama süreleri kısıtlanmaktadır. Bu çalışmada, rüzgar türbinlerinde meydana gelen arızaların nedenleri ile işletme ve bakım konuları ele alınmıştır.

Anahtar Kelimeler: Rüzgar türbini, rüzgar türbini arızaları, işletme ve bakım

\section{Operation and Maintenance for Wind Turbines}

\begin{abstract}
Energy consumption increases due to population growth, industrialization and increased level of comfort. On the other hand, fossil fuels, where most of the energy consumption is provided today, cause climate change and environmental pollution. For this reason, renewable energy sources come to the fore. Among renewable energy sources, wind energy comes to the forefront considering the initial investment and operating costs. Failure and inoperability of wind turbines are among the topics that investors do not want. Considering the mechanical and electrical components of wind turbines, it was observed that the most malfunction was caused by electrical evenings, but the pauses during mechanical malfunctions took longer periods. With the maintenance works to be performed in wind turbines, both malfunctions can be prevented and the downtimes are limited. In this study, the causes of malfunctions in wind turbines and operation and maintenance issues are discussed.
\end{abstract}

Keywords: Wind turbine, maintenance, operation and maintenance

\begin{tabular}{|c|c|}
\hline Geliş/Received & : 02.06 .2020 \\
\hline Kabul/Accepted & : 11.09 .2020 \\
\hline
\end{tabular}




\section{EXTENDED ABSTRACT}

\section{Introduction}

The commercial use of wind energy in electrical power generation has developed rapidly in recent years and has reached levels that can compete with commercial plants in terms of investment costs. For any energy generation technology, the cost of production is variable and is affected by the development level of the technology, working conditions, place of installation and the capacity value of the facilities. Operation and Maintenance (O\&M) costs of wind turbines vary with the lifetime of the facility, and the risk of equipment failure increases with the age of the turbine. O\&M costs of wind turbines have decreased significantly over the last 30 years and account for 20 to $30 \%$ of total life cycle costs for onshore wind turbines. Operation and maintenance costs in offshore wind projects are higher due to the heavy operating conditions at sea, access to the site, complex maintenance work and transmission infrastructure costs. While the cost for wind projects on the coast is approximately 30-60 USD/MWh, it is valued at 71-155 USD / MWh for offshore projects. There are three ways to estimate O\&M costs. The simplest method is to assume that the total annual expense represents a certain percentage of the installation cost and is generally considered to be between 3\% and $5 \%$. More detailed evaluations can be made by examining the annual electricity production cost or hourly electricity production values that generate the revenue. Detailed studies have shown that O\&M costs vary between $15-26 € / \mathrm{MWh}$. In a study conducted by the International Energy Agency using data from 12 different countries, it has shown that O\&M costs are 7-26 €/MWh.

\section{Objectives}

Currently, all three maintenance strategies or their combination are also used in wind farms. Fault maintenance is a typical "runof-the-fault" approach, with preventive maintenance performed before a problem causes a failure, and corrective maintenance scheduled to fix existing plant specific problems. Preventive maintenance is also called usage-based or predictive maintenance. It is done in predetermined situations or for certain periods in relation to the age of the equipment. Researches have shown that the most malfunctions are caused by electrical equipment (about 5.5 failures per ten machine per year) and that the malfunctions in electrical equipment are repaired and reactivated in a very short time ( 1.5 days on average). On the other hand, it has shown that gearbox malfunctions are less frequent (1.5 failures in ten years), but repair takes longer (6 days on average). The least problematic is the hydraulic systems and their repairs take less than half a day.

Combining the number of failures with the number of days the turbine is down allows an estimate of the average loss of efficiency in a decade. Faults in both gearboxes and electrical systems cause an average loss of work for only one day a year.

Condition-based maintenance has the ability to predict the remaining life of the equipment in order to implement the best maintenance strategy before the failure occurs. It is possible to perform checks or monitor some variables using sensors such as temperature, voltage, current, noise or vibration to determine the condition of the equipment.

\section{Results}

Operation and Maintenance costs are a large part of the annual total cost of a wind turbine. For a new turbine, operating and maintenance costs can reach $20-25 \%$ of the total cost per $\mathrm{kWh}$ generated over the lifetime of the turbine. If the turbine is new, the share may only be $10-15 \%$, but this turbine may increase to $20-35 \%$ towards the end of its life. Therefore, operating and maintenance costs are getting more attention, as manufacturers try to significantly reduce these costs by developing new turbine designs that require fewer regular service visits and less turbine downtime.

Operation and maintenance costs are related to a limited number of cost components including:

- Insurance;

- Regular maintenance;

- Repair;

- Spare parts and

- Administration.

Maintenance performed in wind turbines are listed below;

1. Annual preventive maintenance

- Wind turbine preliminary examination at the beginning of the contract

- Preventive maintenance according to the manufacturer's specifications

- Oil change

- Lubrication

- Review of torque and screws

- Measurement of electrical values and temperatures

- Analysis of oils

Supply and comprehensive management of spare parts and consumables

2. Corrective maintenance:

- Identifying and resolving electrical faults

- Replacement of small parts

- Replacement of large parts

- Renewal

- Repair of telecommunication systems

Benefits of Care

- Increasing productivity and profitability (even if more than 15 years)

- Improving security guards

- Cost reduction

- Improving the estimation efficiency of the MW value generated

- Extending the life span

\section{Discussion and Conclusions}

Given the increase in energy consumption and the role of fossil fuels in climate change, it can be expected that wind energy will increase further in the future. Wind turbines are mostly operated in rural areas or in seas. Many difficulties are encountered in the operation and maintenance of wind turbines. Failure to do the necessary maintenance on time or properly causes some problems. While these problems sometimes cause simple malfunctions and stoppage of the turbine, in some cases the turbine becomes completely unusable. Therefore, attention should be paid to maintenance work in wind turbines.

Studies have shown that maintenance in wind turbines has a direct effect on the value of electricity generation. The deterioration or corrosion occurring on the wing surfaces causes a decrease in electricity generation. Vibrations that may arise due to malfunctions in bearings or moving evenings also cause a decrease in energy consumption and, if not resolved in time, causes malfunctions and the turbine to standstill. 


\section{GİİŞ}

Tüm rüzgar türbinleri, aerodinamik kaldırma veya aerodinamik sürükleme kuvvetlerinden yararlanarak çalışır. Aerodinamik kaldırma kuvvetleri rüzgarın yönüne diktir, sürükleme kuvvetleri ise aynı yöndedir. Günümüz rüzgar türbinleri esas olarak, aerodinamik kaldırma kuvvetlerini kullanmak için tasarlanmıştır. Dikey kaldırma kuvveti, rotorun kaldıraç gücü vasıtasıyla gerekli döndürme torkunu üretir.

Rüzgar enerjisinin ticari olarak elektrik enerjisi üretiminde kullanımı son yıllarda oldukça hızlı bir şekilde gelişmiş ve yatırım maliyetleri açısından kömür santralleri ile rekabet edebilecek düzeylere kadar gelmiştir [1]. Herhangi bir enerji üretim teknolojisi için, üretimin maliyeti değişkendir ve teknolojinin gelişmişlik düzeyinden, çalışma koşullarından, kurulduğu yerden ve tesisin kapasite değerinden etkilenir [2]. Rüzgar santralleri temel olarak aşağıdaki faktörlerden etkilenir [3]:

- İşletme ve Bakım (İ\&B) maliyetleri;

- Yıllık enerji üretimi (YEÜ);

- Sermaye maliyetleri;

- Finansman maliyetleri;

- Rüzgar hızı

- Türbin tipi.

Rüzgar türbini üreticilerin türbin teknolojisini geliştirmesine bağlı olarak; yatırım, işletme ve bakım maliyetleri azaltılabilir ve farklı rüzgar koşulları için farklı tasarımlar yapılabilir. Rüzgar enerjisinden üretilecek enerjinin artışını sağlamak için, büyük rüzgar türbinleri ve süpürme alanları, geliştirilmiş kanat aerodinamiği ve daha uzun kuleler geliştirilmekte ve kurulmaktadır [3].

Rüzgar türbinlerinin İ\&B maliyetleri, tesisin kullanım ömrüne göre değişir ve ekipmanın arızalanması riski türbinin yaşı ile birlikte artar. Rüzgar türbinlerinin İ\&B maliyetleri, son 30 yılda önemli ölçüde azalmıştır ve karada kurulmuş rüzgar türbinleri için toplam yaşam döngüsü maliyetlerinin \%20 ila 30'unu oluşturmaktadır [1]. Açık deniz rüzgârı projelerindeki işletme ve bakım maliyetleri, denizdeki ağır çalışma koşulları, sahaya erişim, karmaşık bakım işleri ve iletim altyapısı maliyetleri nedeniyle daha yüksektir. Kıyıdaki rüzgar projeleri için maliyeti yaklaşık 30-60 ABD Doları/ MWh iken denizde kurulan projeler için 71-155 ABD Dolar /MWh'değerlerini bulmaktadir [4].

Rüzgar türbinleri optimum enerji dönüşümünü sağlayabilmek için, rüzgar hızına veya elektriksel tasarıma bağlı olarak karmaşık yapılara sahip olmaktadır [5] ve değişken rüzgar hızlarında bile sabit hızlarda dönebilmelidir. Rüzgar türbini sabit hızı, şanzıman oranına, şebekenin frekansına ve elektrik jeneratörü tasarım özelliklerine bağlı olarak ayarlamaktadır [6]. 
Güç düzenlemesi normal olarak, rüzgar türbininin aşırı yüklenmesini önlemek için rotor kanatları, durma kontrolü veya ikisinin bir kombinasyonu ile yapılır. Rotor üzerine etki eden aerodinamik kuvvetler ve türbinin çıkış gücü, yüksek rüzgar hızlarında azalır.

Rüzgar enerjisi yenilenebilir, uygun maliyetli ve sürdürülebilir bir güç teknolojisi olarak gelişmektedir. Rüzgar türbinlerinin boyutları sürekli olarak artmaktadır ve yeni gelişmeler ile birlikte elektrik şebekelerine daha iyi entegrasyon mümkün olmaktadır. Güç elektroniğinin gelişimi, enerji verimliği daha iyi olan değişken hızlı rüzgar türbinlerinin gelişmesini sağlamıştır. Bir rüzgar türbini tipik olarak ana bileşenleri olan kanatlar, rotor, ana yatak, aktarma organları ve güç modülü ile birlikte 8000 parça veya daha fazlasını içermektedir. Şekil 1, bir rüzgar türbininin ana bileşenlerini göstermektedir.

Enerji endüstrisindeki diğer güç santralleri gibi, rüzgar santralleri de şirketler için hem elektrik üretimine hem de gelir elde etmelerine olanak sağlamıştır. Bununla birlikte, kömür veya gaz santrallerinin aksine, rüzgar santrallerinde bazı farklı zorluklar ortaya çıkmaktadır.

Endüstriyel ölçekte seri rüzgar türbinlerinin üretimi oldukça yenidir ve farklı rüzgar türbin modelleri bir süredir çok sayıda işletmede çalışmaktadır. Rüzgar türbini sektörünün yeni olması nedeni ile mühendis ve uzman teknisyenler bile türbinlerin hangi

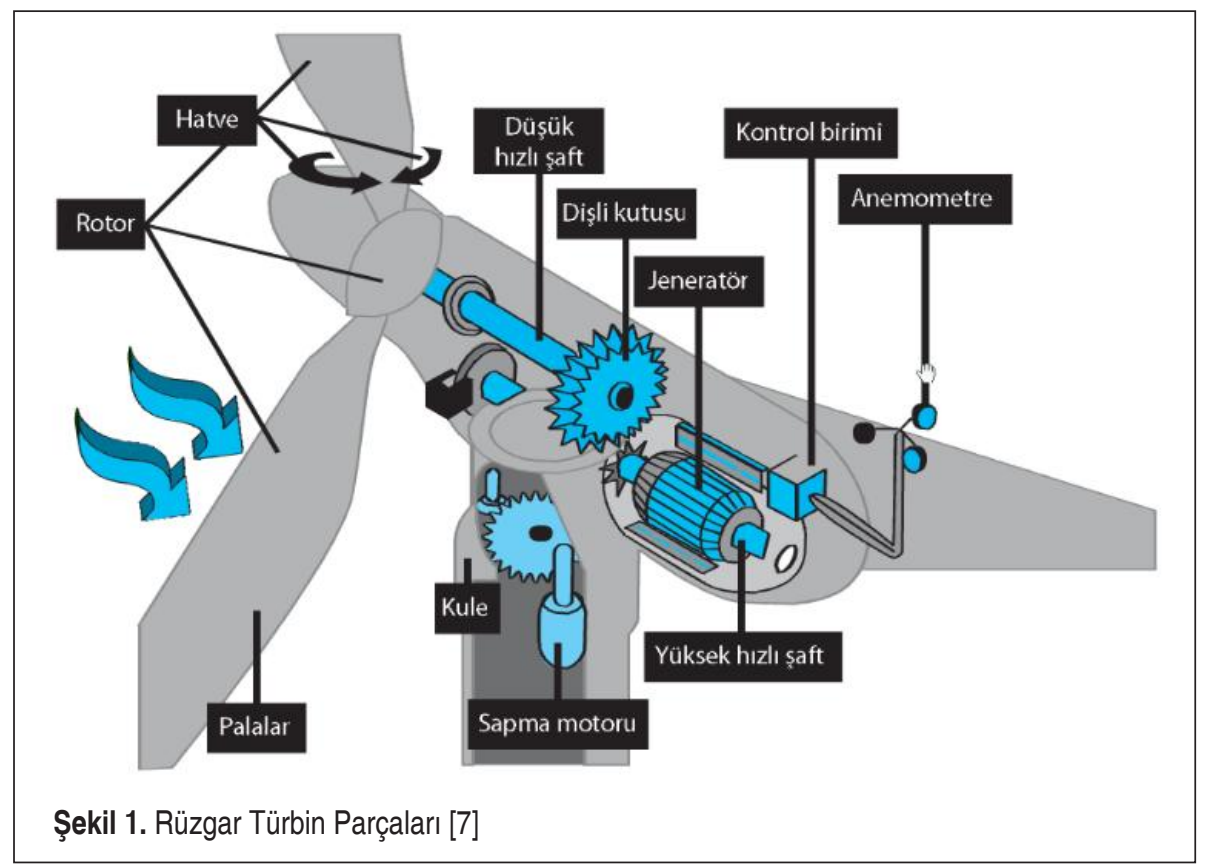


bileşenin ne zaman arıza yapabileceği, arıza meydana gelmeden önce veya sonrasında sorunun nasıl önlenebileceği veya çözüleceği konusunda, ellerindeki veri eksikliği nedeni ile tam olarak bilgi sahibi olamamakktadırlar. Ancak rüzgar türbini işletmecileri, operatörleri ve türbin üreticileri; yürüttükleri projeler ile kırılana veya tamamen devreden çıkıncaya kadar türbinleri çalıştırmak yerine, bakımlarını yaparak çok uzun süreler türbinleri çalıştırmanın mümkün ve önemli olduğunu görmüşlerdir.

Rüzgar türbinlerinin onarımı çeşitli nedenlerle oldukça zordur. Çoğu rüzgar santrali genellikle uzak bölgelerdedir ve işçiler sahada 90 m kadar yükseklikte onarım yapmak zorunda kalmaktadır. Ayrıca, doğal gaz yakıtlı veya kömür yakıtlı santrallerin aksine, operatörler nispeten küçük kapasiteli rüzgar türbinleri nedeniyle bu işlemi birkaç kez tekrarlamaları da gerekebilir.

Rüzgar türbinlerinin İ\&B maliyetlerinin iki bileşeni hayati önem taşımaktadır ve en aza indirgenmesi gerekir: Programlı bakım ve planlanmamış bakım. Parça arızaları planlanmamış durmalara yol açarsa, o zaman elektrik satışları mümkün olmayacağı için ek maliyetler ortaya çıkmaktadır. Bu nedenle bu gibi durumları ortadan kaldırmak ve oluşabilecek arızaları öngörebilmek için çok sayıda çalışma yapılmaktadır.

İ\&B maliyetlerini tahmin etmenin üç yolu vardır. En basit yöntem, yıllık toplam giderin, kurulum maliyetinin belli bir yüzdesini temsil ettiğini varsaymaktır ve genellikle bu değerin $\% 3$ ile $\% 5$ arasında olduğu kabul edilir. Daha ayrıntılı değerlendirmeler, geliri oluşturan yıllık elektrik üretimi maliyeti veya saatlik elektrik üretim değerleri incelenerek yapılabilir. Yapılan detaylı çalışmalarda, İ\&B maliyetinin 15-26 €/MWh arasında değiştiğini göstermiştir. Uluslararası Enerji Ajansı'nın 12 farklı ülkeden gelen verileri kullanarak yaptığ değerinde olduğunu göstermiştir [8]. Şekil 2 de Almanya'da yapılan bir çalışmanın sonuçlarına bağlı olarak, rüzgar türbinlerinde işletme ve bakım giderlerinin dağılımı gösterilmiştir.

Veriler işletme maliyetlerinin türbin büyüklügüünün artmasıyla düştüğünü göstermektedir. Yapılan bir çalışmada, 800-1000 kW aralığında yer alan rüzgar türbinlerinin işletme maliyetlerinin, 420- $490 \mathrm{~kW}$ aralığındaki türbinlerin işletme maliyetinden \%15 daha düşük olduğunu göstermiştir. Daha büyük rüzgar santrallerinin işletme maliyetlerinin, daha düşük değerler alması beklenebilir, çünkü genel giderler daha fazla sayıdaki türbine bölünmektedir [8].

Rüzgar santralinde bakım ve işletme maliyetlerini en aza indirmenin, çok fazla sayıda yolları olduğu konusunda karmaşık teoriler vardır. Rüzgar türbinlerinde çok az ve yüzeysel bakım yapmakla çok fazla ve detaylı bakım yapmak arasında bir denge kurulmalıdır. Fazla, detaylı ve gereksiz yapılacak bakım da bir maliyet olarak ortaya çıkmaktadır.

Bakım stratejilerini planlarken önemli bir diğer araç, bileşen arızalarının olasılığı hak- 


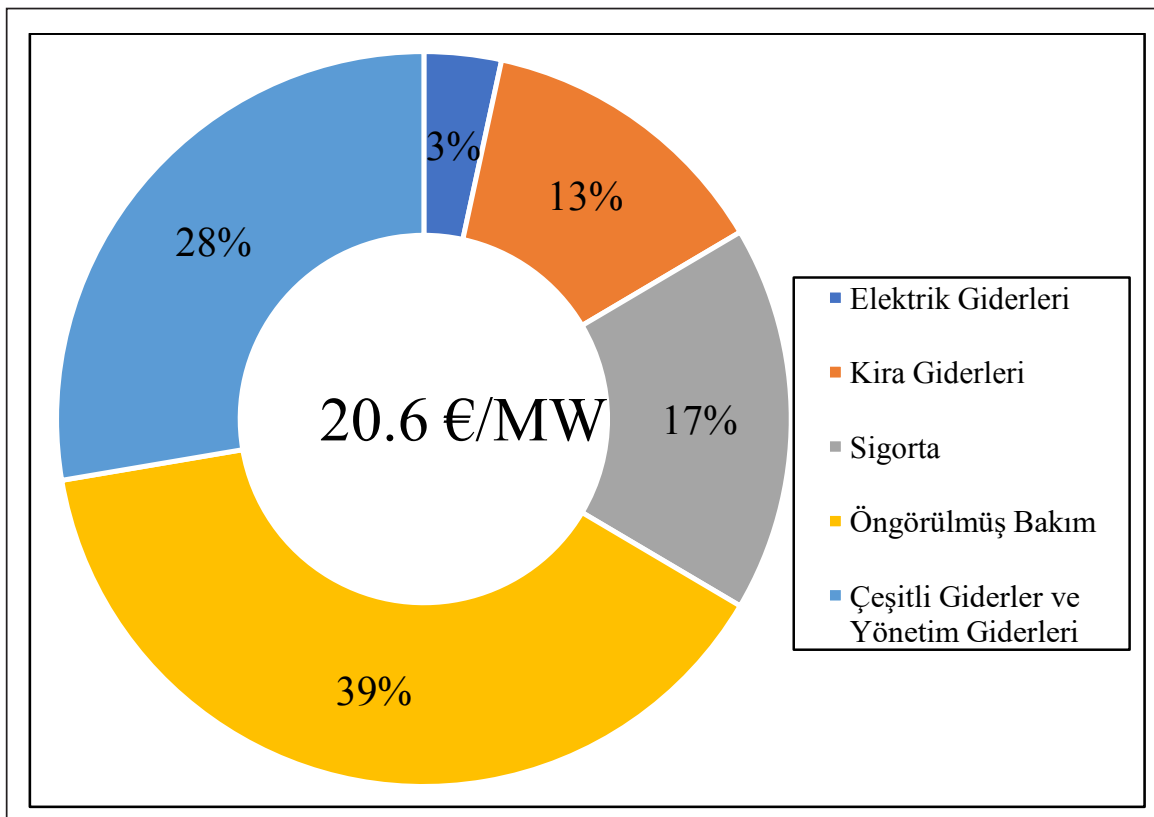

Şekil 2. Rüzgar Türbinlerinde İşletme ve Bakım Giderleri [8]

kında bilgi sahibi olmaktan geçmektedir. Bunun için, ülke çapında ve tek elden rüzgar türbinlerinin izlenmesi, bunların verilerin arşivlenmesi ve arızaların nedenlerinin belirlenmesinin büyük yararlar sağlayacağı düşünülmektedir.

Aynı derecede önemli olan bir diğer konu, türbin arızalanması sırasında geçen sürenin belirlenmesi ve belirli bileşenlerin arızası sonucu oluşabilecek gelirin kaybının belirlenmesidir. Arıza özellikleri makinalerin tasarımına ve kullanım sürelerinin uzunluğuna da bağlıdır.

\section{RÜZGAR TÜRBINİ ARIZALARI VE BAKIM}

Bakım, üretim işlemlerinde en düşük maliyetle optimum kullanılabilirlik, güvenilirlik ve işletilebilirlik seviyelerinin sağlanmasına yardımcı olan bir aktivitedir. Bakım stratejileri genel olarak arıza bakımı, önleyici bakım ve düzeltici bakım olmak üzere üç ana stratejiye ayrılabilir [9].

Halen üç bakım stratejisinin tamamı veya bunların kombinasyonu, rüzgar santrallerinde de kullanılmaktadır. Arıza bakımı, tipik bir "arızadan kaçma” yaklaşımıdır, bir sorunun bir arızaya yol açmasından önce önleyici bakım yapılır ve mevcut tesise özgü sorunları gidermek için düzeltici bir bakım planlanır. Önleyici bakım, kullanıma dayalı veya öngörücü bakım olarak da adlandırılır. Ekipmanın yaşıyla ilişkili olarak ön- 
ceden belirlenmiş durumlarda veya belirli sürelerle yapılır [10]. Bakımın az yapılması durumu gibi fazla yapılması durumu da tercih edilmemektedir [11].

Duruma dayalı bakım, arıza oluşmadan önce en iyi bakım stratejisini uygulamak için ekipmanın kalan ömrünü tahmin etme yeteneğine sahiptir. Ekipmanın durumunu belirlemek için sıcaklık, voltaj, akım, gürültü veya titreşim gibi sensörleri kullanarak kontroller yapmak veya bazı değişkenleri izlemek mümkündür. Durum izleme süreci; çevrimiçi veya çevrimdışı olabilir ve üç temel adımdan oluşur [12]:

- Veri toplama - ekipman sağlığıyla ilgili verileri toplamak;

- Veri işleme - analitik doğrulama, toplanan verilerin anlaşılması ve iyileştirilmesi;

- Karar verme - uzun vadeli tesisin çalışır durumda olmasını en düşük maliyetle sağlamak için hangi bakım stratejisinin ideal olduğuna karar vermek.

Rüzgar türbinlerindeki arızalar, düşük kalite, kötü tasarım ve üretim standartları, inşaat ve montaj eksiklikleri, yerel işletme koşulları, iletim sistemi tasarımı ve genel bakım gibi çeşitli nedenlerden kaynaklanabilir [13]. Şanzıman arızaları en uzun duruş sürelerine neden olan mekanik arızalardandır [14]. Yaklaşık 800 adet rüzgâr türbininde yapılan bir çalışmada türbinlerin büyüklüğüne bakılmaksızın türbinlerin çoğunluğu için arıza tespitinin \%90'ın üzerinde olduğu görülmüştür [13]. Hahn ve diğ. [14], şanzıman (dişli kutusu) arızalarının en uzun aksama sürelerine neden olduğu ve teknolojiler iyileştikçe ortalama aksama süresinin azaldığı sonucuna varmışlardır. 15 y1llık bir süre zarfında Almanya'da 1500'den fazla rüzgar türbini ile ilgili olarak yapılan bir anket sırasındaki alt sistemlerdeki arıza oranları ve duruş süreleri, jeneratör arızalarının rüzgar türbinlerindeki toplam arıza sayısının yaklaşık \% 4’ünü temsil ettiğini göstermektedir. Rüzgar türbinlerinde meydana gelebilecek arızaların çok ciddi sonuçları olduğu ve türbinleri tamamen kullanılamaz duruma getirdiği arızalar da meydana gelebilmektedir (Şekil 3.)
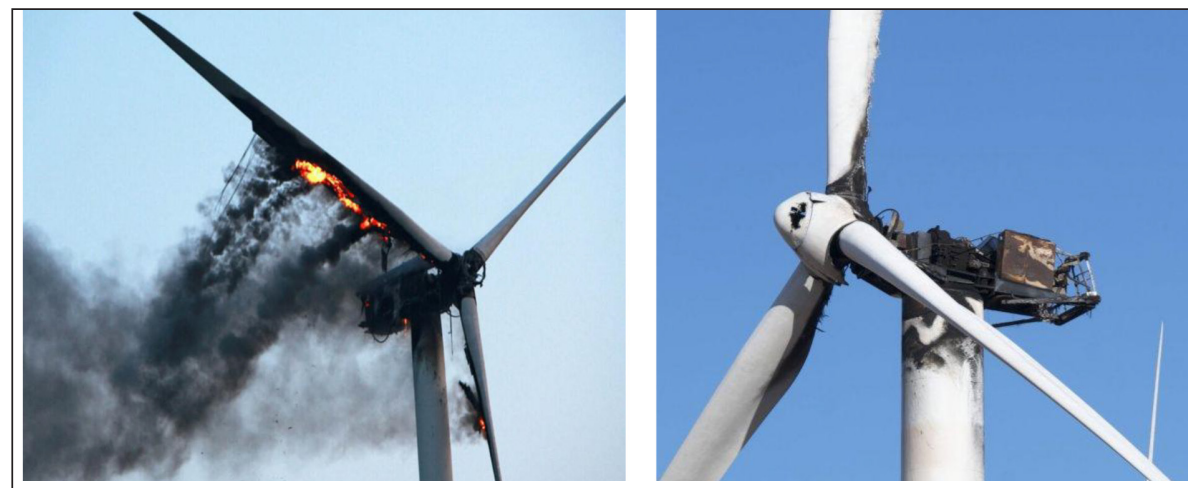

Şekil 3. Türbin Arızası ve Yangın [15, 16] 
Rüzgar türbinlerinin elektriksel aksamlarında ana arıza nedeni, yataklar ve sargılarla ilgilidir. Aşağıdaki bileşenler, indüksiyon jeneratörleri kullanan rüzgar jeneratörlerinde meydana gelen çoğu arızanın nedenleri arasında yer almaktadır [17]:

- Rulmanlar;

- Stator ve rotordaki sargi arızaları;

- Rotor kafesleri ve uçlari;

- Kayma halkalari;

- Statordaki manyetik takozlar;

- Soğutma tesisi.

Yapılan araştırmalar en çok arızanın elektrik ekipmanlarından kaynaklandığını (her on makina yılda yaklaşık 5.5 arıza) ve elektrik ekipmanlarında meydana gelen arızaların çok kısa sürelerde (ortalama 1.5 gün) tamir edilerek yeniden faaliyete geçirildiğini göstermiştir. Diğer yandan dişli kutusu arızalarının daha seyrek (on yılda $1.5 \mathrm{kez}$ arıza) olduğunun ancak tamiratının ise daha uzun süreler aldığını (ortalama 6 gün) göstermiştir. En az soruna neden olan ise hidrolik sistemlerdir ve tamiratları yılda yarım günden daha az süre almaktadır.

Arıza sayısının türbinin çalışmadığı gün sayısı ile birleştirilmesi, on yıldaki ortalama verimlilik kaybının tahmin edilmesini sağlamaktadır. Hem dişli kutularındaki hem de elektrik sistemlerindeki arızalar, yılda ortalama sadece bir gün çalışma kaybına neden olmaktadır.

\subsection{Stator Arızaları}

Rotor ve stator sargılarının yalıtım arızasına neden olan ana yaşlanma mekanizmaları 1sıl etkiler, titreşim gerilmeleri, güç dönüştürücülerindeki voltaj yükselmeleri ve sıcaklık değişimlerinden dolayı malzeme bozulmalarıdır (Şekil 4). Çevresel koşullar yalıtım bozulmasını hızlandırabilir ve nemli çalışma koşullarından kaçınılmalıdır. Kısa devrelerin oluşumu aşırı ısınmadan kaynaklanır ve zamanla artar. Değişken hızlı endüksiyon makinalerinde güç dönüştürücülerinin neden olduğu voltaj yükselmeleri, sargı yalıtım hatalarının da kaynağıdır. Çıkış kablosu ile jeneratör arasındaki empedans farklılıkları, kablo uzunluğu arttıkça ve yarı iletkenlerin anahtarlama frekansı arttıkça daha şiddetli hale gelen yansıyan dalgaları oluşturur [14].

\subsection{Rulman Arızaları ve Bakım}

Yatak arızaları büyük ölçüde rüzgar jeneratörü arızalarına neden olur ve sık karşılaşılan nedenleri yanlış montaj veya yanlış hizalamanın yanı sıra zayıf yağlama, aşırı ısınma ve mekanik kırılmadır [13]. Yüzey sıkıntısı, korozyon, elektrik akımı akışı ve aşırı yüklenme ile birlikte normal yaşlanma sırasında yatak aşınması da rulman arıza- 
sına neden olabilir. Bakım uygulamalarının, yatak arıza oranlarını azaltmak için yatak yağlama programlarına uyması oldukça önemlidir. Hasarlı rulmanlar, stator ve rotor arasındaki havanın eşit dağılımını bozar ve rotorun aşırı titreşımlerine neden olabilir. $\mathrm{Bu}$ titreşimler giderilmez ise, stator ve rotor arasında temasa neden olabilir, bu da her iki bileşenin de yıkıcı hasarına neden olur.

\subsection{Türbin Kanatlarında Bakım}

Bazı durumlarda kanatlarda meydana gelen arızalar nedeni ile bütün bir kanat veya türbinin tümü kullanılamaz hale gelebilmektedir (Şekil 4). Geleneksel olarak, türbin kanatlarının bakımına, türbinin diğer bileşenlerinin onarımı ve bakımından daha az dikkat edilmiştir. Oysa ki, verimli çalışmayan kanatlar, titreşim yaratabilmekte ve şanzıman arızalarına neden olmaktadır. Rüzgar türbini sektöründe, genel olarak, koruyucu bakım programları, bakım gereksinimlerinin tahmin edilebilirliği nedeniyle türbinlerin iç mekaniğine odaklanılmıştır. Dahili bileşenler için tipik koruyucu bakım planları 3, 6 ve 12 aylık çalışma programlarına ayrılır. Doğal olarak, kanat onarımlarını planlamak daha zordur. İmalat, nakliye, kule yapımı ve montajında kanatlarda hasarlara neden olabilir. Bununla birlikte, kanatlarda bakım gereksinimi sahada en sık görülen erozyon, hava durumu ve diğer faktörlerden kaynaklanmaktadır. Tahmin edilebilirlik ve geçmişe dair veri eksikliği, kanatların önleyici bakımını zorlaştırmaktadir [19].
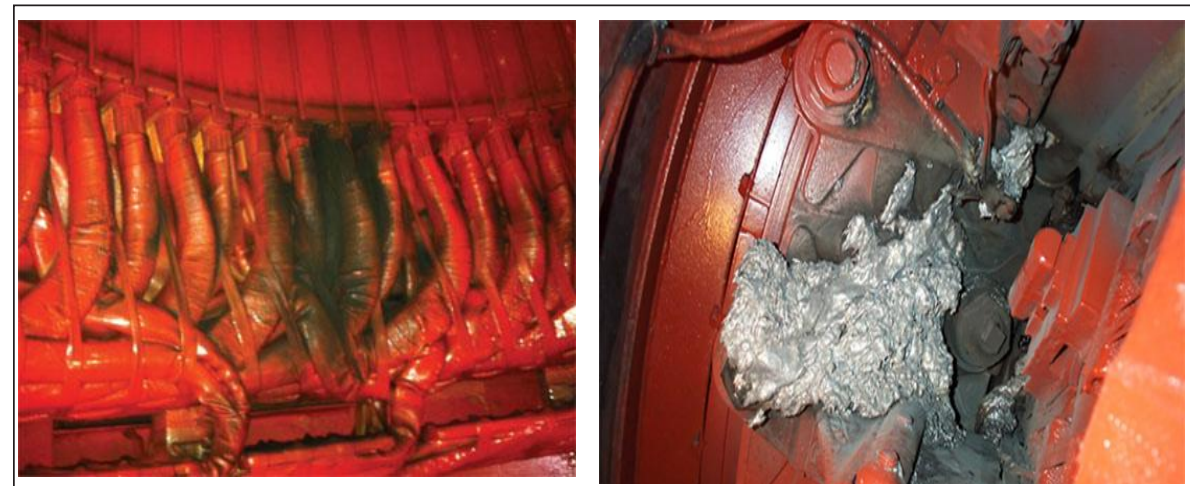

Şekil 4. Rüzgar Türbinlerinin Rotor Sargılarında Meydana Gelen Arızalar [18]

Ticari türbinlerin devir hızları 90 m/s'den daha fazla olabilir. Bu hızlarda yağmur damlaları küçük taşların çarpma etkisi gibi etki yaratabilir ve kum üfleyen bir plazma kesicinin erozyon gücüne sahiptir. Bu durum zaman içinde kanat yüzeylerinde pürüzlülüğün artmasına neden olmaktadır. Çalışmalar kanat pürüzlülüğünü ve kanatların üzerinde biriken artıkların rüzgar türbini performansını \%5 ila 30 oranında azaltabi- 
leceğini göstermiştir [20]. Kanatların yüzey veya kenarlarında oluşabilecek arızalar türbin verimini düşüreceğinden mutlaka bakım yapılarak giderilmelidir (Şekil 5).

Arıza süresini en aza indirmek ve enerji verimliliğini artırmak için, önleyici bir bakım programı uygulamak ve sorunlu alanları belirlemek de dahil olmak üzere, uygulamaları hızlı bir şekilde yapmak kritik öneme sahiptir. Rüzgar türbinleri için yatırımın geri dönüşünün uzun olduğu göz önünde bulundurulduğunda, türbinlerin arıza yapması ve

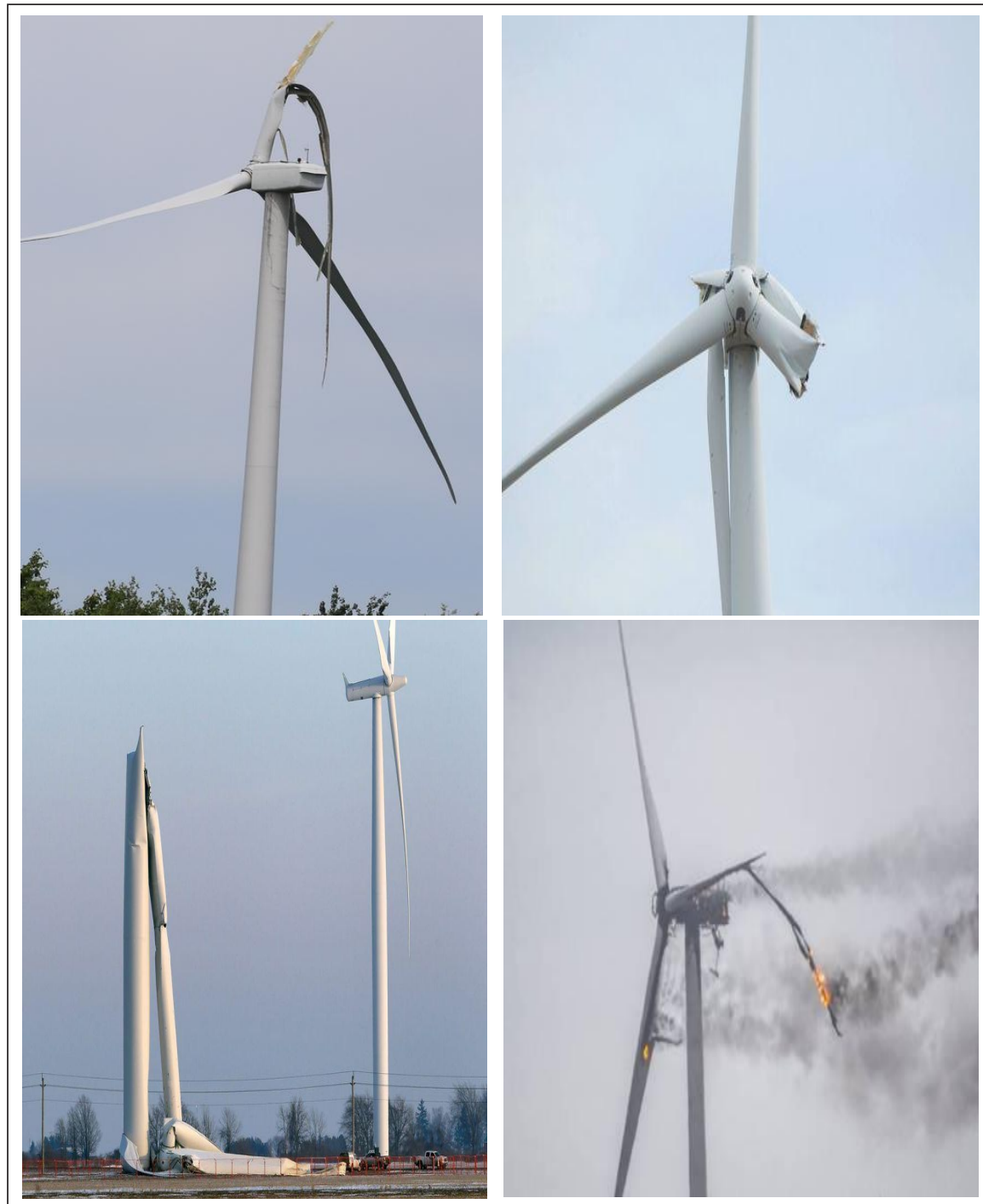

Şekil 5. Rüzgar Türbini Kanatlarında Meydana Gelen Büyük Hasarlar [21, 22, 23] 
duraksamaların minimize edilmesi ve bakım ve onarımların hızlı ve düşük maliyetlerle yapılması rüzgar enerjisi sektörü için büyük önem kazanmaktadır.

\subsection{Türbinlerde Yağlama ve Dişli Kutusunda Bakım}

Rüzgar türbinleri pahalı makinalerdir ve yağlama sistemi bu makinanin iyi çalışmasını sağlamak için kritik öneme sahiptir. "Rüzgar türbininin birçok farklı parçasının, dişli kutusu akışkanlarından hidrolik yağlara kadar bir dizi yağlayıcı gres yağıyla yağlanması gerekir. Bir rüzgar türbininin şanzımanının doğru şekilde yağlanması, iyi bir bakım yapılması bir rüzgar türbininin ömrünün uzatılmasında önemli katkılar sağlar. Rüzgar türbini dişli kutularında kullanılmak üzere geliştirilen; rüzgar türbinlerinin aşırı sıcaklıklar kullanılmasına olanak sağlayan, açık deniz rüzgar türbinleri için tuzlu sudan ve olası korozyondan etkilenmeyen ve bütün bu etkilerden türbinleri koruyan ve çok zor koşullarda özelliklerini kaybetmeyen sentetik veya mineral yağlar geliştirilmiştir.

Dişli kutusundaki kullanılan yağlar, değiştirmeden üç ila beş yıl arasında kullanılabilmektedir. Dişli kutusu yağının değiştirmesi çok maliyetidir. Şanzımanın arızalanması veya şanzımanın değiştirilmesi işletmeciler tarafından istenmeyen bir durumdur. Bu süreçte hem üretim durmakta, hem bakım masrafları yüksek olmakta, hem de özel vinçlerin kiralanarak dişli kutuları değiştirilebildiği için maliyetler çok yükselmektedir. Ancak türbinin yağlaması gerektiren tek parçası dişli kutusu değildir. Jeneratör yatakları ve türbin kanat yataklarının da yağlanması gerektirir ve kanatların üzerinde yağlama noktaları vardır. Rüzgar türbin kanatları, esasen kanadın gövdeye bağlandığı kısmı kuşatan yataklara sahiptir, böylece operatörler türbin kanat açısını rüzgar hızına ve yönüne göre optimize edebilirler.

Şanzıman rüzgar türbinlerinde ek bir stres yaratmakta ve yağın yeterli bir film mukavemeti sağlaması konusunda zorluklar oluşturmaktadır. Yağlama yağlarının oksidasyon direncinin optimize edilebilmesi ve düşük sıcaklıkta akışkanlığının korunabilmesi için katkı maddeleri kullanılması gerekmektedir. Bu konularda özellikle yağ sektöründe araştırma ve geliştirme çalışmaları sürdürülmektedir. Rüzgar türbini sektöründe, daha yüksek kuleler, daha uzun rüzgar türbini kanatları ve daha yüksek güçler (MW) oldukça, yeni zorluklar ortaya çıkmaktadır

Rüzgar türbinleri, aşırı yükleri, basıncı ve gerilimi düzenli olarak idare eden karmaşık bir makinalerdir. Rüzgar türbinlerinin en yüksek kapasitede ve verimde ça1şmasını sağlamak için bakım oldukça önemlidir. Türbin yağlaması, rüzgar enerjisi çiftliklerinde ekipmanı koruma işleminin sadece bir parçasıdır. Rüzgar türbinlerinde, planlı bakımın ayrıca filtre değiştirme ve cıvata torklama gibi hizmetleri de oldukça önemlidir. 

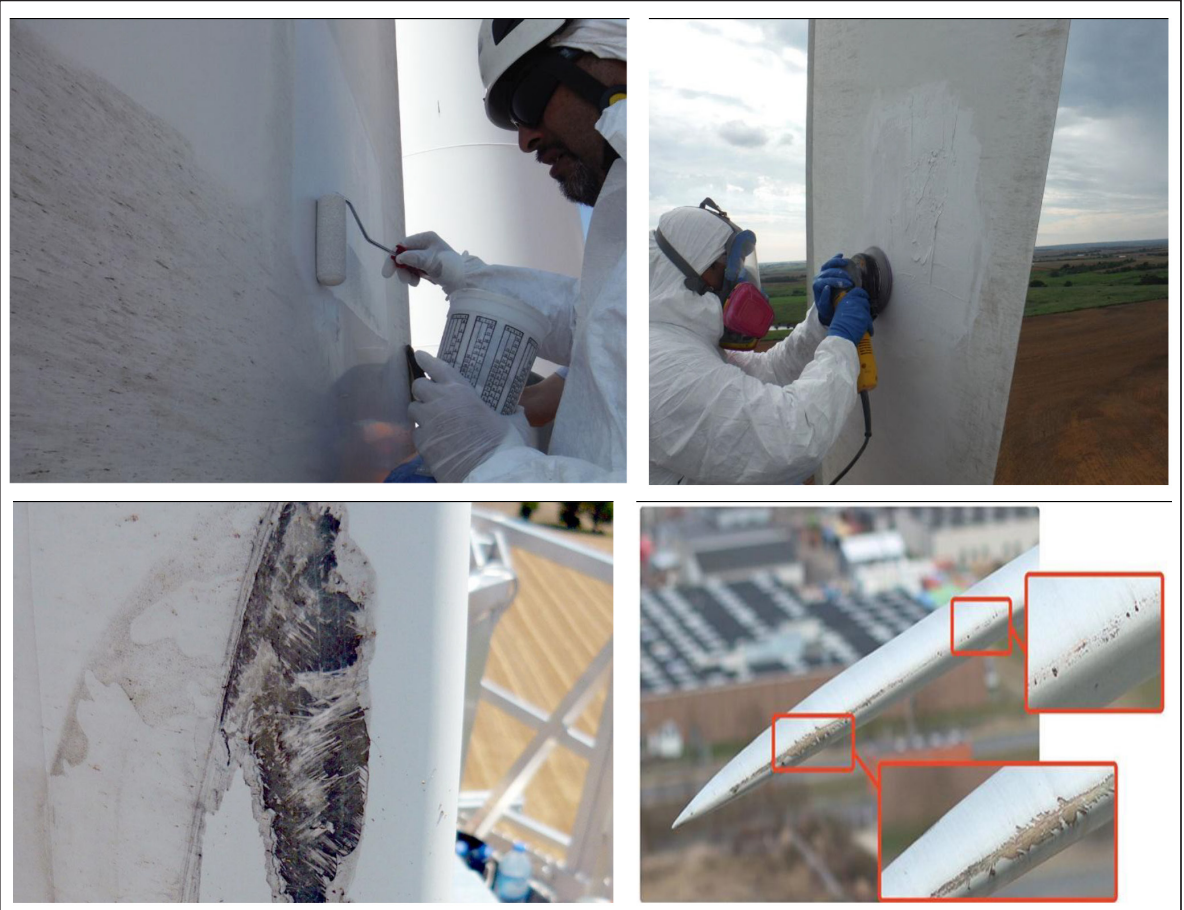

Şekil 6. Rüzgar Türbin Kanatlarında Meydana Gelen Arızalar ve Bakımları [24, 25, 26]

\section{AÇIK DENİZ RÜZGAR TÜRBINLERINDE BAKIM}

Rüzgar türbinlerinde, özellikle açık deniz rüzgâr santrallerinde, bileşen arızalarıyla uğraşmanın sonuçları ve maliyetleri çok daha kritiktir, zira tamir gemilerinin bölgeyi ziyaret etmesi ve hataların giderilmesi için zaman ayırması hem zaman almakta hem de bakım maliyetlerini artırmaktadır. Şanzıman gibi kritik bir parçanın arızalanması diğer bileşenlere zarar verebilir ve bu nedenle de olası sorunlara önceden belirlenmesi ve uyarı verilmesinin sağlanması oldukça önemlidir.

Açık denizlerde rüzgar türbinleri çok daha fazla enerji üretir. Ancak, denizlerde pas önemli bir problem olarak ortaya çıkmaktadır. Sermaye yatırımını ödemek için, açık deniz rüzgar santrallerinin en az 25 yıl boyunca çalışabilmeleri gerekmektedir bu ise ancak ayrıntılı bir bakımla mümkündür. Gelecekte, yenilikçi malzemeler ve teknolojiler sayesinde daha iyi ve daha uygun maliyetli bir hale getirilebilir. Yapılan araştırmalar, optimize edilmiş bir tamir işlemi için koruyucu bir filmler geliştirerek açık deniz rüzgar türbinlerinin kullanımında ortaya çıkan problemleri ortadan kaldırmaya çalışmaktadırlar. Açık deniz rüzgar türbinlerinin bakım ve onarımı oldukça zordur 
çünkü tüm işler denizde ve her türlü havada yapılmalıdır. Korozyona karşı koruyucu kaplamalar yapılması da oldukça zor bir süreçtir. Rüzgar türbinlerinin su altında kalan kısmının da su üstünde bulunan bölümün de korozyona karşı korunması büyük önem taşımaktadır.

\section{RÜZGAR TÜRBINLERINDE YAPILAN BAKIM ÇALIŞMALARI}

Genel olarak bakıldığında bakım ile ilgili farklı kategoriler mevcuttur. Bunlar şu şekilde siralanabilir;

\section{1 Önleyici Bakım}

Bakım, önceden belirlenmiş aralıklarla veya belirtilen kriterlere göre yapılır ve bir ürünün işleyişinin arıza veya bozulma olasılığını azaltmayı amaçlar. Önleyici bakım, bakımın planlı ve periyodik olduğu anlamına gelir. Arızaların oluşmasını önlemek için bakım eşit aralıklarla yapılır.

\subsection{Programlı Bakım}

Belirlenmiş bir zaman çizelgesine veya belirlenmiş bir aralıkta yapılan bakım.

\section{3 Şartlara Dayalı Bakım}

Performans veya parametre izlemeye ve sonraki işlemlere dayalı önleyici bakımdır. Bileşenlerin geçmişi hakkındaki veriler, bakıma ne zaman ihtiyaç duyulduğunu tahmin etmek için istatistiksel yöntemlerle birlikte kullanılır. Ne zaman bakıma ihtiyaç duyulduğunu tahmin etmek, bileşenin nasıl ve neden başarısız olduğu belirlemek için yapılan bakım çalışmalarıdır.

\subsection{Düzeltici Bakım}

Arıza tespitinden sonra yapılan ve bir öğeyi istenen işlevini yerine getirebileceği bir duruma getirme amaçlı bakımdır. Bileşenler çalıştığı sürece düzeltici bakım yapılmaz. Parçalardan biri arıza yaptığı zaman tamir edilir veya kaldırılır.

\subsection{Bakım Optimizasyonu}

Bakım optimizasyonu için genel amaç, toplam maliyetleri en aza indirmek veya bakım kaynaklarını en üst düzeye çıkarmaktır.

\subsection{Veri Analizi}

İzlemenin ilkeleri yeni değildir, ancak giderek ön plana çıkmakta olan karmaşık bilgi işlem analizi ile ölçülen verilerin yorumlanması ve analizi konusunda son yıllarda çok 
büyük yol alınmıştır. Dişli kutusundan alınacak titreşim seviyelerinin analizi muhtemel ortaya çıkabilecek arızalar konusunda bilgi verebilir. Titreşim çalışan bir makinanin durumu hakkında bilgi vermektedir. Titreşimde meydana gelecek değişimler, makinanın aksamlarında bir farklılık olduğu anlamına gelebilir. Bu nedenle dakikalık veya saatlik titreşim seviyelerini ölçüp kaydederek, yeni ölçülen titreşim verileri ile karşılaştırmak ve farklılık ortaya çıkarsa kullanıcıya önceden haber vermek olası arızaların önüne geçilmesine yardımcı olacaktır.

Titreşim seviyesi kademeli olarak artış gösteriyorsa, kullanıcıya bir alarm gönderilir. Bu seviye tehlike seviyesinin çok altında bile olsa izlemede yarar olabilir.

\subsection{Güvenirlik Merkezli Bakım (GMB)}

GMB, koruyucu bakım ve düzeltici bakım arasında denge kurmak ve doğru zamanda doğru bileşen için doğru koruyucu bakım faaliyetlerini en uygun maliyetli çözüme ulaştırmak için sistematik bir yöntem sunar. GMB yöntemi, bakım planlarını belirlerken güvenilirlik konularına odaklanan yapısal bir yaklaşımdır.

Rüzgar türbinlerinde yapılan bakımlar aşağıda sıralanmıştır;

\section{Yıllık önleyici bakım}

- Sözleşme başlangıcında rüzgar türbini ön incelemesi

- Üreticinin özelliklerine göre önleyici bakım

- Yağ değişimi

- Yağlama

- Tork ve vidaların gözden geçirilmesi

- Elektriksel değerlerin ve sıcaklıkların ölçülmesi

- Yağların analizi

- Yedek parçaların ve sarf malzemelerinin temini ve kapsamlı yönetimi

\section{Düzeltici Bakım:}

- Elektrik arızalarının belirlenmesi ve çözülmesi

- Küçük parçaların değiştirilmesi

- Büyük parçaların değiştirilmesi

- Yenileme

- Telekomünikasyon sistemlerinin onarımı

\section{Bakımın Sağladığı Yararlar}

- Verimlilik ve karlılığın arttırılması (15 yıldan fazla bile olsa) 
- Güvenlik görevlilerinin iyileştirilmesi

- Maliyetlerin azaltılması

- Üretilen MW değerindeki gücün tahmin etkinliğinin iyileştirilmesi

- Ömrü uzatma

\section{RÜZGAR TÜRBINLERINNDE İŞLETME VE BAKIM}

İşletme ve Bakım maliyetleri, bir rüzgar türbininin yıllık toplam maliyetinin büyük bir bölümünü oluşturmaktadır. Yeni bir türbin için, işletme ve bakım maliyetleri, türbinin kullanım ömrü boyunca üretilen $\mathrm{kWh}$ başına toplam maliyetin \%20-25'ini bulabilmektedir. Türbin yeniyse, pay yalnızca \%10-15 olabilir, ancak bu türbin ömrünün sonuna doğru \%20-35 seviyelerine çıkabilmektedir. Bu nedenle de, üreticiler daha az düzenli servis ziyaretleri ve daha az türbin aksama süresi gerektiren yeni türbin tasarımları geliştirerek bu maliyetleri önemli ölçüde azaltmaya çalıştıklarından, işletme ve bakım maliyetleri daha fazla dikkat çekmektedir.

İşletme ve bakım maliyetleri, aşağıdakileri içeren sınırlı sayıda maliyet bileşeniyle ilgilidir:

- Sigorta;

- Düzenli bakım;

- Tamir etmek;

- Yedek parçalar ve

- İdaresi.

$\mathrm{Bu}$ maliyet bileşenlerinden bazıları nispeten kolay bir şekilde tahmin edilebilir. Sigorta ve düzenli bakım için, rüzgar türbininin toplam kullanım ömrünün önemli bir kısmını kapsayan standart sözleşmeler yapmak mümkündür. Tersine, onarım ve ilgili yedek parçaların maliyetlerini tahmin etmek çok daha zordur. Her ne kadar tüm maliyet bileşenleri türbin büyüdükçe artma eğiliminde olsa da, tamir ve yedek parça maliyetleri özellikle türbin yaşından etkilenir; düşük başlar ve zamanla artar.

Rüzgar enerjisi endüstrisinin göreceli yeni olmasından dolayı, 20 yıllık ömür beklentisine ulaşmış sadece birkaç türbin vardır. Bu türbinler de şu anda piyasada bulunanlardan çok daha küçüktür.

Almanya, İspanya, İngiltere ve Danimarka'daki deneyimlere dayanarak, işletme ve bakım maliyetlerinin, türbinlerin toplam ömrü boyunca, üretilen kWh başına rüzgar enerjisi başına yaklaşık 1,2 ila 1,5 eurocent (c €) olduğu tahmin edilmektedir. İspanya'daki veriler, bu miktarın \%60'ından daha azının kesinlikle türbin ve tesisatların 
İ\&B'na gittiğini ve geri kalanının işçilik maliyetleri ve yedek parçalar arasında eşit olarak dağıldığını göstermektedir. Kalan \%40, sigorta, arsa kiralama ve genel giderler arasında eşit olarak dağılmıştır. Yeni ve daha büyük türbinler için daha düşük İ\&B maliyetlerine yönelik eğilimi göstermektedir. Bu nedenle, üç yıllık bir türbin için, İşletme ve Bakım maliyetleri yaklaşık $3.5 \mathrm{c} € / \mathrm{kWh}$ 'den düşmüştür; eski $55 \mathrm{~kW}$ türbinler için yeni $600 \mathrm{~kW}$ makinaler için $1 \mathrm{c} € / \mathrm{kWh}$ 'den az olmaktadır [27].

\section{SONUÇ}

Enerji tüketiminin artması ve iklim değişiminde fosil yakıtların rolü göz önüne alındığında rüzgar enerjisinin gelecekte daha da artması beklenebilir. Rüzgar türbinleri çoğunlukla kırsal alanlarda veya denizlerde kurularak işletilmektedir. Rüzgar türbinlerinin işletilmesinde ve bakımında birçok zorluk ile karşılaşılmaktadır. Gerekli bakım işlemlerinin zamanında veya gerektiği gibi yapılmaması bazı problemlerin ortaya çıkmasına neden olmaktadır. Bu problemler bazen basit arızalara ve türbinin duraksamasına neden olurken, bazı durumlarda türbinin tamamen kullanılamaz duruma gelmesine neden olmaktadır. Bu nedenle de rüzgar türbinlerinde bakım çalışmalarına önem verilmesi gerekmektedir.

Rüzgar türbinlerinde bakımın elektrik üretim değeri üzerinde de doğrudan etkisi olduğu yapılan çalışmalarda görülmüştür. Kanat yüzeylerinde meydana gelen bozulmalar veya korozyon elektrik üretiminin düşmesine neden olmaktadır. Rulmanlarda veya hareketli akşamlarda meydana gelebilecek arızalar nedeni ile ortaya çıkabilecek olan titreşimler de hem enerji tüketiminin düşmesine neden olmakta, hem de zamanında giderilmez ise arızalara ve türbinin duraksamasına neden olmaktadır.

Bütün bu ve benzeri nedenlerle rüzgar türbinlerinde bakım çalışmaları yapılmalı ve önleyici bakım konusuna önem verilmelidir.

\section{KAYNAKÇA}

1. IRENA. 2018. "Renewable Power Generation Costs in 2017”. Abu Dhabi: International Renewable Energy Agency.

2. Wu B, Lang Y, Zargari N, Kouro S. 2011. "Power Conversion and Control of Wind Energy Systems”. Piscataway, NJ, USA: IEEE Press; John Wiley \& Sons.

3. Boccard, N. "Capacity Factor of Wind Power Realized Values vs. Estimates". Energy Policy 2009;37(7):2679-2688.

4. Lazard, 2017." Lazard's Levelized Cost of Energy Analysis". Version 11.0.

5. Saheb-Koussa D, Haddadi M, Belhamel M, Koussa M, Noureddine S. 2012. "Modeling and Simulation of Wind Generator With Fixed Speed Wind Turbine Under MATLAB-Simulink." Energy Procedia. 18:701-708. 
6. Bustos, G., Vargas, L. S., Milla, F., Sáez, D., Zareipour, H., \& Nuñez, A. 2012. “Comparison of Fixed Speed Wind Turbines Models: A Case Study." In IECON 2012-38th Annual Conference on IEEE Industrial Electronics Society (pp. 961-966). IEEE.

7. Köseoğlu, H. 2019. "Rüzgar Enerjisi Nedir, Elektrik Enerjisi Santralleri." http://www. huseyinkosoglu.com/wp-content/uploads/2016/01/R\%C3\%BCzgar-Enerjisi-Nedir.pdf. . İnternet Erişim, Kasım 2019.

8. Milborrow, D. 2010. "Breaking down the cost of wind turbine maintenance". Wind Power, https://www.windpowermonthly.com/article/1010136/breaking-down-cost-wind-turbine-maintenance. İnternet Erişim, Kasım 2019.

9. Kuiler, I., Adonis, M., \& Raji, A. 2018. "Preventive Maintenance and Fault Detection for Wind Turbine Generators Using a Statistical Model. In Fault Detection and Diagnosis.” IntechOpen. Canada, October 25-28. 2012.

10. Tian Z, Jin T, Wu B, Ding F. 2011. "Condition Based Maintenance Optimization for Wind Power Generation Systems Under Continuous Monitoring." Renewable Energy. 36(5): 1502-1509

11. Agrawal KK, Pandey GN, Chandrasekaran K. 2013. "Analysis of the Condition Based Monitoring System for Heavy Industrial Machineries.” IEEE International Conference on Computational Intelligence and Computing Research, Enathi. pp. 1-4

12. Yang W, Tavner PJ, Crabtree CJ, Feng Y, Qiu Y. 2014. "Wind Turbine Condition Monitoring: Technical and Commercial Challenges.” Wind Energy. 17(5):673-693.

13. Gowdar RD. 2016. Mallikarjune Gowda MC. "Reasons for Wind Turbine Generator Failures: A Multi-Criteria Approach for Sustainable Power Production." Renewables: Wind, Water, and Solar. 3(1):9

14. Hahn B, Durstewitz M, Rohrig K. 2007. "Reliability of Wind Turbines." Wind Energy., Berlin Heidelberg: Springer; pp. 329-332. DOI: 10.1007/978-3-540-33866-6_62.

15. MECF, 2019. "Metropolitan Engineering Consulting and Forensics, Cause and Contrıbutıng Factors of Failure of Geared Wind Turbines". https://sites.google.com/site/metropolitanforensics/cause-and-contributing-factors-of-failure-of-wind-turbines

16. Smith, C. 2014. Fires are Major Cause of Wind Farm Failure, According to New Research, https://www.imperial.ac.uk/news/153886/fires-major-cause-wind-farm-failure/. İnternet Erişim, Kasım 2019.

17. Alewine K, Chen W. 2012. "A Review of Electrical Winding Failures in Wind Turbine Generators." IEEE Electrical Insulation Magazine. 28(4):8-13.

18. EP. 2019. "Efficient Plant, Stopping Repeat Wind-Farm Generator Failures," https:// www.efficientplantmag.com/2013/09/stopping-repeat-wind-farm-generator-failures/. İnternet Erişim, Kasım 2019.

19. Behrends, L. 2019. "Full maintenance and basic maintenance" https://www.deutsche-windtechnik.com/onshore-full-maintenance-and-basic-maintenance. İnternet Erişim, Kasım 2019. 
20. WP. 2011. Wind Power, Planning Maintenance for Wind Turbine Blades, https://www. windpowerengineering.com/operations-maintenance/planning-maintenance-for-windturbine-blades/. İnternet Erişim, Kasım 2019.

21. Shreve, E. 2018. "Wind Turbine Topples in Chatham-Kent". https://windsorstar.com/ news/local-news/wind-turbine-topples-in-chatham-kent. İnternet Erişim, Kasım 2019.

22. NWW. 2016. "National Wind Watch, Exelon: Mechanical failure led to turbine collapse", https://www.wind-watch.org/news/2016/05/07/exelon-mechanical-failure-led-to-turbine-collapse/. İnternet Erişim, Kasım 2019.

23. NNYW.2018. "Northern NY Wind", http://www.nnywind.com/photos.html. . İnternet Erişim, Kasım 2019.

24. BR. 2019. "Blade Repair Quality Blade Repair Pays", https://fairwindres.com/wind-industry-maintenance/blade-repair/. . İnternet Erişim, Kasım 2019.

25. BS, 2019, "Blade Service, Our Service Portfolio", https://www.mb-bladeservice.com/en/ leistungen.html. . İnternet Erişim, Kasım 2019.

26. FT, 2019. "Force Technology, Wind turbine towers and rotor blades are exposed to the whims of the weather. Drone inspection provides a visual or thermographic image of the state of the components". https://forcetechnology.com/en/services/drone-inspection-ofwind-turbines-onshore-and-offshore. İnternet Erişim, Kasım 2019.

27. WEF. 2019. "Wind Energy the Fact, Operation and Maintenance Costs of Wind Generated Power", https://www.wind-energy-the-facts.org/operation-and-maintenance-costs-of-wind-generated-power.html. . İnternet Erişim, Kasım 2019. 